\title{
ADHD and Cerebellar Vermis Tumor: DTI Analysis of an Incidental Finding
}

\section{TDAH e Tumor de Vermis Cerebelar: Análise de DTI de um Achado Incidental}

\author{
Maurício Martins Baldissin ${ }^{1,2}$ Edna Marina de Souza 3,4 \\ ${ }^{1}$ Department of Surgery, Jundiaí Medical School, Jundiaí, Brazil \\ Address for correspondence Maurício Martins Baldissin, MD, MSc, \\ 2 Neurodiagnosis and Neurotherapeutics Clinic, Jundiaí, Brazil \\ Clínica de Neurodiagnose \& Neuroterapêutica, 160, Barão de Teffé St, \\ ${ }^{3}$ Medical Physicist, Department of Biomedical Engineering, \\ 4th floor, Jundiaí, SP, Brazil Zip-code: 13208-760 \\ Faculdade de Engenharia Elétrica e de Computação, Universidade \\ Estadual de Campinas (Unicamp), Campinas, Brazil
}

${ }^{4}$ Biomedical Engineering Center, Unicamp, Campinas, Brazil

Arq Bras Neurocir 2016;35:239-243.

\begin{abstract}
Keywords

- DTI

- childhood central nervous system tumors

- ADHD

- incidental findings

The increase in number of magnetic resonance imaging (MRI) scans for investigation of neurological diseases in childhood and adolescence leads to increase of incidental findings of central nervous system (CNS) tumors in these stages of life. Among MRI techniques, diffusion-weighted imaging (DWI) and diffusion tensor imaging (DTI) have been increasingly used in brain studies. These images are based on random motion of water molecules in the body, which can change depending on constitution and geometry of biological tissues, as well as the existence of pathologies.

This paper reports the use of DTI and DWI to evaluation of a CNS tumor incidentally detected in a patient diagnosed previously with Attention Deficit Hyperactivity Disorder (ADHD). He was diagnosed at age 9 and has been treated with medicines and psycho-pedagogical therapies. At age 15 a MRI detected a cerebellar vermis tumor with a volume of $2 \mathrm{~cm}^{3}$. Due to parental decision, the patient did not undergo any surgical intervention. During the follow-up period we did not observe significant changes in tumor size or diffusion directions in the tumor and surrounding brain tissues. The main brain tracts presented normal diffusion patterns, both in terms of size and geometry. The DTI analysis showed that lesion was quite homogeneous and isotropic, with no significant restriction of diffusion. There also were no significant diffusion pattern changes in other regions of the brain which possibly could be related to ADHD. So, given the characteristics of lesion and the patient's clinical symptoms, it cannot be directly related to ADHD.
\end{abstract}

Recebido

June 3, 2016

Aprovado

July 18, 2016

published online

September 5, 2016
DOI http://dx.doi.org/

10.1055/s-0036-1588000. ISSN 0103-5355.
Copyright $@ 2016$ by Thieme Publicações License terms

Ltda, Rio de Janeiro, Brazil 


\section{Resumo}

Palavras-Chave

- DWI

- DTI

- tumor do sistema nervoso central na infância

- TDAH

- achados incidentais
O maior número de exames de Ressonância Magnética (RM) para a investigação de doenças neurológicas na infância e adolescência leva a um aumento de achados incidentais de tumores do Sistema Nervoso Central (SNC) nessas fases da vida. Dentre as técnicas de RM, imagens ponderadas por difusão (DWI) e do tensor de difusão (DTI) vêm sendo cada vez mais empregadas em exames exploratórios. Essas imagens são baseadas no movimento randômico das moléculas de água no organismo, que varia em função da constituição e geometria dos tecidos biológicos, bem como da existência de patologias. Este trabalho relata o emprego das DWI e DTI para avaliação de um tumor no SNC detectado de forma incidental em um paciente com diagnóstico prévio de Transtorno do Déficit de Atenção (TDAH). Ele recebeu esse diagnóstico aos 9 anos, sendo tratado com medicações e suporte psicopedagógico. Aos 15 anos a RM apontou um tumor de $2 \mathrm{~cm}^{3}$ no vermis cerebelar. Por decisão dos pais, não houve qualquer intervenção cirúrgica. Durante o período de acompanhamento não foram observadas mudanças no tamanho do tumor ou direção de difusão na lesão e nas estruturas ao seu redor. Os principais tratos cerebrais apresentaram padrões de difusão normais, em termos de tamanho e geometria. A análise das DTI mostrou que a lesão era bastante homogênea e isotrópica, não apresentando restrição à difusão. Não foram encontradas alterações significantes na difusão em outras regiões do cérebro. Assim, dadas as características da lesão e as manifestações clínicas, não relacionamos o tumor diretamente ao TDAH.

\section{Introduction}

Central nervous system (CNS) tumors are the second most common neoplasm in children, after leukemia. However, their mortality and morbidity rates are three times higher than in leukemia patients. According to literature, astrocytomas are the most common primary brain tumors in children. Posterior fossa and supratentorial tumors occur with approximately the same incidence. While supratentorial tumors are more common among children aged 2 to 3 years, infratentorial tumors are found predominantly among children aged 4 to 10 years. Symptoms of childhood CNS tumors vary according to the patient's age and the characteristics of the disease. Patients may present with enlarged skull circumference, nausea, vomiting, headache and lethargy. In some cases, decreased visual acuity, seizures, ataxia and hemiparesis may also occur. However, thereare cases, in which the patient does not present symptoms and the tumor is found indirectly. ${ }^{1}$
DTI has been used for tumor characterization, surgery planning and research., ${ }^{2,3}$ These images combine MRI techniques with diffusion measurements, so each pixel carries information about the random of water molecule displacement in biological tissues. DTI can be calculated using DWI obtained in at least six different directions, providing indexes as to the directionality and magnitude of water molecule displacement, which may vary for different tissues and depending on pathological conditions. ${ }^{4}$-Table 1 shows the main calculated DTI indexes (DTIis) and their corresponding meanings. The indexes described below are: mean diffusivity (MD), fractional anisotropy (FA), relative anisotropy $(R A)$, volume ratio $(V R)$, skewness $(S)$, sphericity $\left(C_{s}\right)$, linearity $\left(C_{1}\right)$ and planarity $\left(C_{p}\right)$. For the study of brain tumors, DTI has been used to infer tumor cellularity and its possible classification. In general, high-grade tumors show high cellular density, which causes a reduced diffusion in solid portions and surrounding tissues and changes

Table 1 DTlis and their meanings

\begin{tabular}{|l|l|}
\hline DTli & Description \\
\hline MD & Magnitude of diffusion, in units of $\mathrm{mm}^{2} / \mathrm{s}$ \\
\hline FA & Grade of anisotropy; ranging from 0 (isotropic diffusion) to 1 (anisotropic diffusion) \\
\hline RA & Ratio of anisotropic and isotropic portions of tensor \\
\hline VR & Ratio of an ellipsoid and a sphere volume; ranges from 0 (isotropic diffusion) to 1 (anisotropic diffusion) \\
\hline$S$ & Indicates if the tensor is oblate or prolate \\
\hline$C_{S}, C_{1}$ and $C_{P}$ & $\begin{array}{l}\text { Geometric indexes that provide information about shape of the tensor; they can be plotted in a barycentric } \\
\text { coordinate system. Each one ranges between } 0 \text { and } 1 \text { and their sum is equal to } 1\end{array}$ \\
\hline
\end{tabular}


diffusion directions. ${ }^{5}$ Moreover, these images can be helpful for surgical planning, providing information on brain connectivity. It is therefore possible to obtain knowledge on lesion areas, which can be resected with little damage to healthy brain tissues. ${ }^{6,7}$

ADHD is a common psychopathological disorder in children, affecting $\sim 5.3 \%$ of children and adolescents. In many of these cases, ADHD does not diminish during adolescence, and can persist into adulthood as a full clinical condition or as a partial syndrome in $60 \%$ of the cases, becoming a chronic condition. A prevalence of $\sim 3.4 \%$ has been shown in individuals aged $18-44$ years. ${ }^{8,9}$ In this pathology, the purpose of diagnostic imaging is to identify common patterns in brain metabolism and/or structures before and after therapy. Volumetric MRI measurements of 107 children showed that those with ADHD, who did not respond to Methylphenidate (MTP) therapy, had a thinner medial prefrontal cortex than children who responded to medication. ${ }^{10}$ A reduced volume of the corpus callosum has also been associated with a reduced response to medication. ${ }^{11}$ In some cases, ADHD may be associated with other pathologies or even mask them. A study described a pineal gland germinoma in a patient that was diagnosed with ADHD and treated with MTP for 3 years. After the patient reported blurred vision for 6 weeks, a more accurate investigation of the pathology detected the lesion. ${ }^{12}$

Given this context, this study describes the use of DTI to evaluate a brain tumor incidentally found in an adolescent suffering from ADHD.

\section{Case Description}

A 16-year-old male patient presenting symptoms of hyperkinetic disorder as of age 5 , as well as a disorganized and excessive motor activity and attention deficit. At age 9, his school and behavioral problems increased, leading to the ADHD diagnostic. A treatment with MTP was purposed. The patient did not show problems in oral or written communication and his electroencephalogram (EEG) was normal. Du- ring the neurological evaluation, imbalances in developmental forces and rhythms were observed. The recommended action was to reduce media stimuli and the intake of psychostimulant foods, as well as provide support to help overcome specific learning difficulties. Mealtimes and sleep-wake cycles were also controlled and adjuvant anthroposophic medication was applied, which improved his clinical condition. ${ }^{13,14}$ At the onset of puberty, the patient's behavior worsened (patient became aggressive toward his family), despite the improvement of his school performance. At age 15, the first brain MRI was performed to detect ADHD-related anatomical changes. The scan identified an expansive process located in the upper portion of the cerebellar vermis, in the midline, in the posterior-anterior direction, measuring 2 cubic centimeters, bulging into the fourth ventricle. The lesion presented hyperintensities on T2 and FLAIR (-Fig. 1), with no apparent diffusion restriction and no postcontrast enhancement on T1 and multiplanar reformatting. The findings suggested a pilocytic astrocytoma, although this tumor is usually found in cerebellar hemispheres. Following the family's decision, the patient underwent conservative treatment; no biopsy was made, nor was the lesion removed. One year later, the MRI did neither show changes in lesion size or location, nor in diffusion standards, which suggested a low-grade glial tumor. All other exams were normal, and there were no classic signs of expansive posterior fossa tumors, such as intracranial hypertension (headache/vomiting, bradycardia, hypertension) and changes in balance and movement. The follow-up MRI images with DTI were obtained on a 3-Tesla Siemens Verio MRI system (Siemens, Erlangen, Germany).

\section{Discussion}

For DTI analysis, we used the ExploreDTI software. ${ }^{15}$ From the tensor we extracted eigenvalues and based on them, we calculated the DTIis (-Table $\mathbf{1}$ ). The mean values and standard deviation of these indexes ( - Table 2 ) were obtained from a Region of Interest (ROI) surrounding the tumor
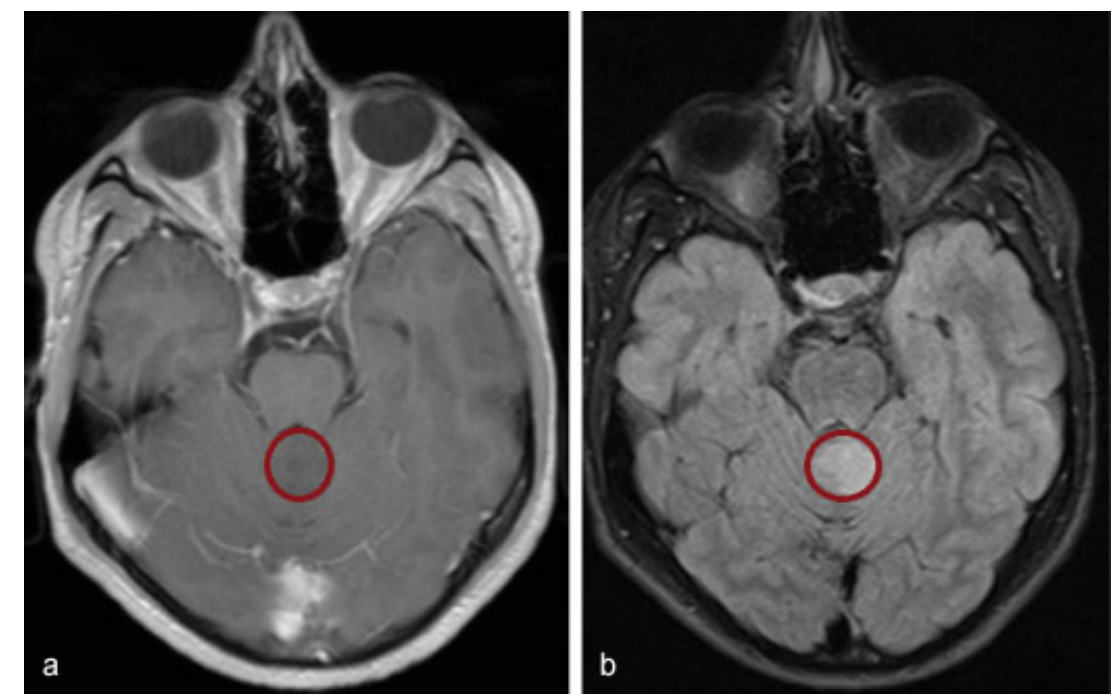

Fig. 1 T1 (a) and T2 (b) FLAIR images highlighting the tumor area. 
( -Fig. 2a). The diffusion ellipsoid, the registration between diffusion ellipsoid and directional diffusion image, as well as the directional diffusion image calculated are also shown (-Fig. 2b-d). Tumor MD and FA values suggested a low-grade and homogeneous lesion, with no significant diffusion restrictions. According to literature, low-grade astrocytomas are the tumors, whose diffusion characteristics come closest to those found in this study. ${ }^{5}$ The calculated anisotropy indexes also point to an isotropic lesion, because there is no preferential diffusion direction, as observed in the surrounding tissues. Geometric DTlis confirm the isotropic aspect of the lesion, because $C_{s}$ is close to 1 and $C_{1}$ and $C_{p}$ are low, indicating high tensor sphericity and diffusion isotropy. In addition to the DTIis, we analyzed the Coefficient of Variation (CV) for directional images (-Fig. 3). On these maps, each color represents diffusion along different orientations (blue: inferior-superior; green: anterior-posterior; red: right-left). Additionally, hypointense areas are related to low-magnitude and directionally dependent diffusion (isotropic diffusion) and hyperactive intense regions reflect high-magnitude and directional diffusion (anisotropic diffusion). We did not observe significant changes in directional diffusion near the tumor or surrounding brain areas. The main tracts, even near the tumor, show normal diffusion patterns.

The studied patient presented several symptoms, which are typical for ADHD. The MRI scan detected a tumor, whose characteristics cannot be directly associated with this disor-
Table 2 DTlis calculated for the tumor

\begin{tabular}{|l|l|l|}
\hline Parameter & Mean & Standard Deviation \\
\hline MD $\left(\mathrm{mm}^{2} / \mathrm{s}\right)$ & $\mathbf{1 . 1 0} \times \mathbf{1 0}^{-3}$ & $4.010^{-4}$ \\
\hline FA & 0.34 & 0.08 \\
\hline RA & 0.24 & 0.27 \\
\hline VR & 0.92 & 0.24 \\
\hline$C_{s}$ & 0.71 & 0.39 \\
\hline$C_{1}$ & 0.11 & 0.04 \\
\hline$C_{p}$ & 0.18 & 0.18 \\
\hline
\end{tabular}

der. Since the family did not authorize a tumor biopsy, which is the gold standard for classifying and characterizing lesions, the patient's follow-up was restricted to MRI. No abnormal diffusion patterns or DTIis values that are typical for tumors and cortical changes related to behavioral and psychological disorders were found in other brain regions. Directional diffusion CV images (-Fig. 3) did not show significant changes in the diffusion along the main brain tracts, which, if present, would indicate connectivity changes, which may be related to ADHD.

Cerebellar vermis tumors often lead to poor motor coordination and poor balance, as well as to other neurological symptoms, such as those associated with intracranial hypertension syndrome. However, we have to consider that the cerebellum acts in learning and behavior. Contrary to a studied report,
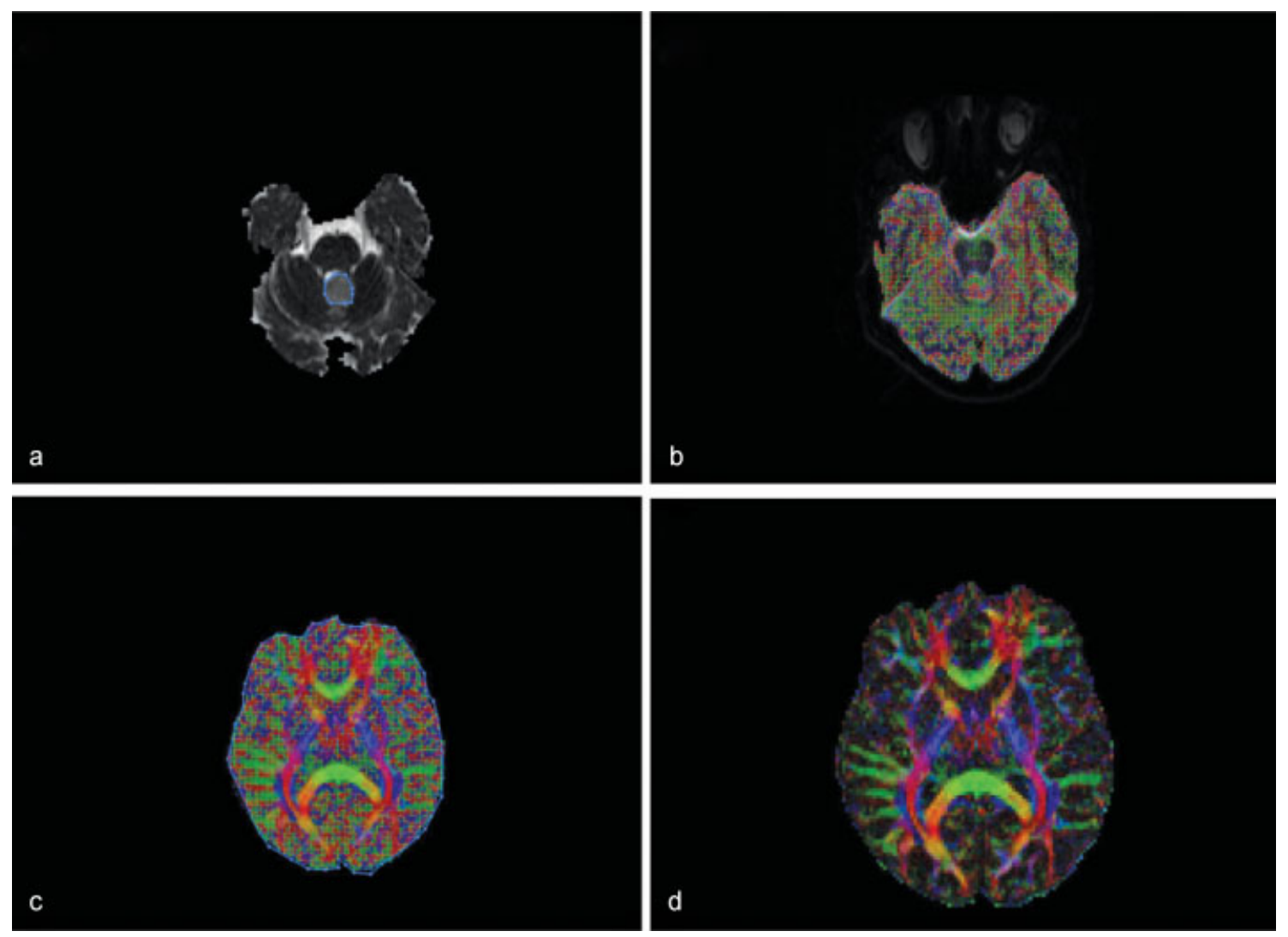

Fig. 2 (a): T2 image with a ROI highlighting the tumor. (b) MD map with diffusion ellipsoids. (c) Corregistration of diffusion ellipsoids and tracts with T2 image. (d): Color-coded directional map of tracts. Each color is related to diffusion in different directions. Blue: inferior-superior; green anterior-posterior; red: right-left. 


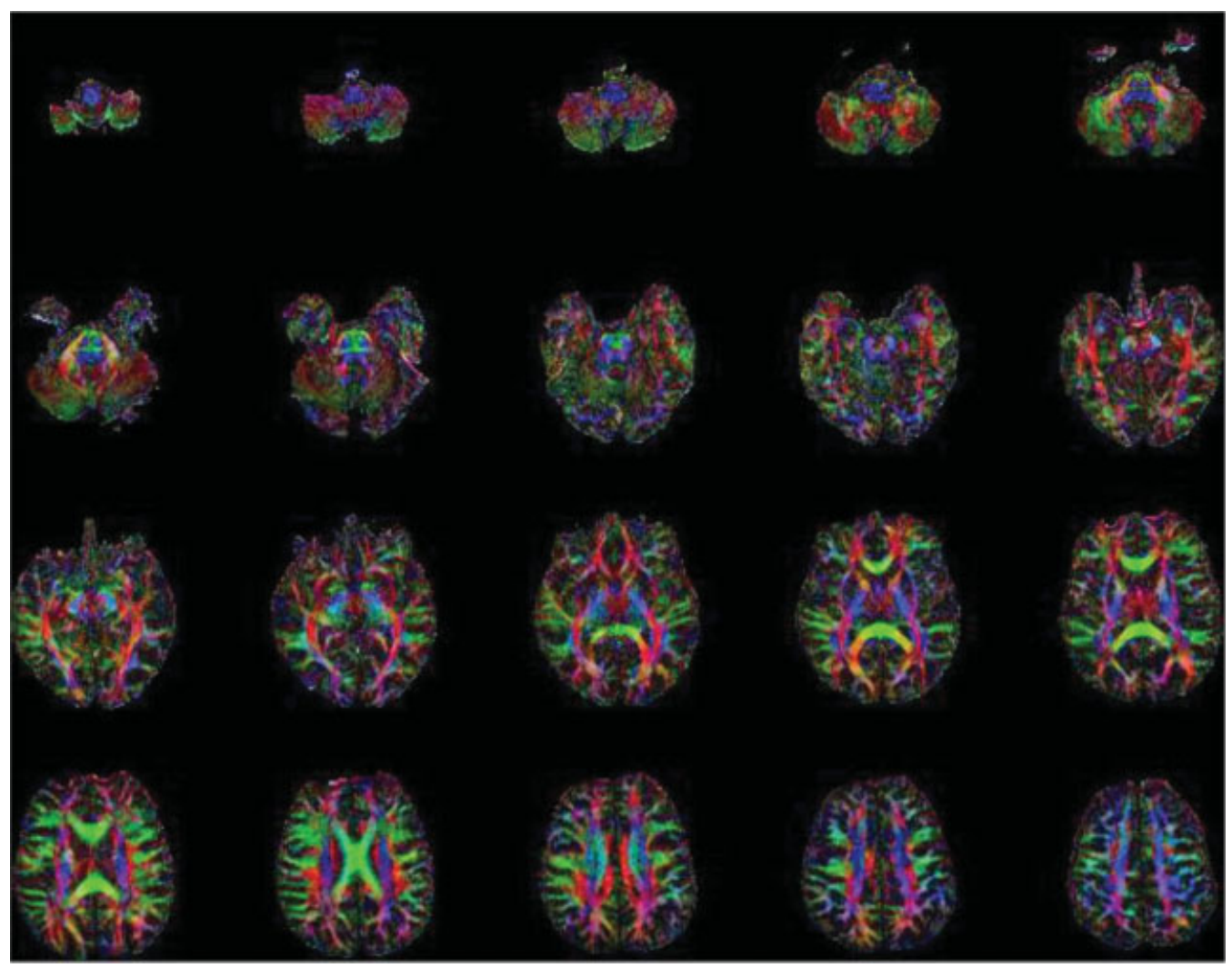

Fig. $3 \mathrm{CV}$ maps for diffusion directionality images.

this particular patient does not present any symptoms that can be directly related to tumor expansion or even structural changes in cortical areas that may be associated to ADHD or other behavioral and psychological disorders, which are prevalent in this case report. The main brain tracts presented normal diffusion patterns, both in terms of size and geometry.

\section{Conclusion}

Currently, DWI and DTI have proven to useful in the investigation of CNS diseases, including brain tumors and pathogenesis of ADHD. In the reported case, the search for cortical changes that could be related to ADHD resulted in the detection of a cerebellar vermis tumor.

\section{References}

1 Patel S, Bhatnagar A, Wear C, et al. Are pediatric brain tumors on the rise in the USA? Significant incidence and survival findings from the SEER database analysis. Childs Nerv Syst 2014;30(1):147-154

2 Baehring JM, Fulbright RK. Diffusion-weighted MRI in neurooncology. CNS Oncol 2012;1(2):155-167

3 Souza EM, Baldissin MM, Castellano G, Costa ET. Imagens de Ressonância Magnética Ponderadas por Difusão e Mapas de ADC Aplicados ao Estudo de Tumores Cerebrais: atualidades e perspectivas. Neurociências e Epilepsia. 3. 1 ed. São Paulo, Brasil.: Plêiade.; 2011. p. 115-20

4 Bammer R. Basic principles of diffusion-weighted imaging. Eur J Radiol 2003;45(3):169-184

5 Yamasaki F, Kurisu K, Satoh K, et al. Apparent diffusion coefficient of human brain tumors at MR imaging. Radiology 2005;235(3): 985-991
6 Tatsuzawa K, Owada K, Sasajima H, Yamada K, Mineura K. Surgical strategy of brain tumors adjacent to the optic radiation using diffusion tensor imaging-based tractography. Oncol Lett 2010; 1(6):1005-1009

7 Stadlbauer A, Hammen T, Grummich P, et al. Classification of peritumoral fiber tract alterations in gliomas using metabolic and structural neuroimaging. J Nucl Med 2011;52(8): 1227-1234

8 Arruda MA, Querido CN, Bigal ME, Polanczyk GV. ADHD and mental health status in Brazilian school-age children. J Atten Disord 2015;19(1):11-17

9 Polanczyk G, Rohde LA. Epidemiology of attention-deficit/hyperactivity disorder across the lifespan. Curr Opin Psychiatry 2007; 20(4):386-392

10 Shaw P, Lerch J, Greenstein D, et al. Longitudinal mapping of cortical thickness and clinical outcome in children and adolescents with attention-deficit/hyperactivity disorder. Arch Gen Psychiatry 2006;63(5):540-549

11 Semrud-Clikeman M, Filipek PA, Biederman J, et al. Attentiondeficit hyperactivity disorder: magnetic resonance imaging morphometric analysis of the corpus callosum. J Am Acad Child Adolesc Psychiatry 1994;33(6):875-881

12 Cunniffe G, Murthy R, Beigi B. Attention deficit hyperactivity disorder: diagnosis and treatment masking the ophthalmic clinical presentation of a pineal gland tumour in a teenager. Int Ophthalmol 2010;30(6):727-730

13 Baldissin M. Percepciones Humanas: Antroposofía y Neurociencias. Madrid, Espanha: IAO Arte Editorial; 2014

14 Baldissin M. Percepções humanas: Antroposofia e Neuro ciências. 1 ed. São Paulo, Brasil: Editora Antroposófica; 2014

15 Leemans AJB, Sijbers J, Jones DK, Eds. ExploreDTI: a graphical toolbox for processing, analyzing, and visualizing diffusion MR data. 17th Annual Meeting of Intl Soc Mag Reson Med; 2009; Hawaii, USA. 